\title{
Voltage measurements over the CAM-1 submarine cable between Madeira Island and Portugal mainland
}

\author{
Fernando A. Monteiro Santos, António Soares, Luís Trindade, Rita Nolasco, Helena Rodrigues, and ISO-3D team* \\ Departamento de Fisica and Centro de Geofisica da Universidade de Lisboa, Campo Grande, Ed. C8, Piso 6, 1749-016 Lisboa, Portugal
}

(Received May 11, 2001; Revised January 9, 2002; Accepted February 2, 2002)

\begin{abstract}
Data of electrical voltage measured between the ends of the CAM-1 cable, during fifteen months, have been analysed in order to determine the electrical stability of the cable and to obtain some preliminary information related to water transport. The monthly average of the potential measured during days with low geomagnetic activity suggests a periodicity of 120 days that was tentatively interpreted as having origin in water flow. These results show a small trend that is compatible with no drift in the cable. The mean electric field estimated from quiet days is $0.206 \pm 0.022 \mathrm{mV} / \mathrm{km}$. If the variations of this potential are attributable to ocean water transport a total water flow of $\pm 0.09 \mathrm{~cm} / \mathrm{s}$ is estimated. This value represents a maximum value for temporal variations of the spatially averaged water-flow velocity.
\end{abstract}

\section{Introduction}

There are several retired telecommunications cables in use for scientific purposes (see e.g., Sanford, 1982; Larsen and Sanford, 1985; Chave et al., 1992; Fujii et al., 1995; Palshin, 1996; Flosadottir et al., 1997; Vanyan et al., 1998; Fujii and Chave, 1999, among several others). The largest numbers of these cables are installed in the Pacific Ocean area. In the Atlantic Ocean there are only 3 cables with measurements in progress (Flosadottir, personal communication): the TAT-8 (between Tukerton in USA, Penmarch in France and Widemouth in England), the CAM-1 and the PENCAN2ext (between Grand Canary and Tenerife). There are also references to some measurements (19 days) in the cable between Tuckerton and Lands End (Lanzerotti et al., 1985) and in the cable TAT-6 (between Rhode Islands and France), carried out several years ago. The geophysically important sources for large-scale cable voltage have been already mentioned by Sanford (1971; see also Meloni et al., 1983; Chave and Luther, 1990): 1) geomagnetic field variations originated by time-variations in the ionosphere and magnetosphere electric current systems, 2) motions of the sea-water through the geomagnetic field and 3) leakage of telluric currents associated with the toroidal geomagnetic field at the core-mantle boundary.

The decommissioning of the CAM-1 cable between Porto Novo in Madeira Island and Sesimbra on the Portuguese mainland (Fig. 1) in 1995, provides us with an excellent opportunity to contribute to the measurement of earth po-

* Other members of the ISO-3D: J. M. Miranda (CGUL), N. Lourenço and J. Luís (U. Algarve), A. Flosadottir (HALO), A. Junge (U. Frankfurt), M. Sinha, L. MacGregor, S. Dean, N. Barker, S. Riches and Z. Cheng (U. Cambridge/U. Southampton).

Copy right(C) The Society of Geomagnetism and Earth, Planetary and Space Sciences (SGEPSS); The Seismological Society of Japan; The Volcanological Society of Japan; The Geodetic Society of Japan; The Japanese Society for Planetary Sciences. tential at a large scale. The geographical coordinates of the cable ends are $38^{\circ} 25^{\prime} \mathrm{N}, 9^{\circ} 50^{\prime} \mathrm{W}$ (Sesimbra) and $32^{\circ} 39^{\prime} \mathrm{N}$, $16^{\circ} 48^{\prime} \mathrm{W}$ (Porto Novo). The length of the cable is $1150 \mathrm{~km}$, with 35 unpowered repeaters. The impedance of the cable is approximately $5500 \mathrm{ohm}$. At the Sesimbra terminus the cable is sunk in sea sediments and used as ground. In fact, the cable was cut $2 \mathrm{~km}$ away from the coast and thrown to the ocean, when it was decommissioned. At the Madeira terminus the cable runs into a cellar under the old Marconi office building in Porto Novo. This provides a stable temperature environment. At this end one of the old telecommunications standard five-foot-long ground rod that is sunk in the sea is used as ground.

The voltage difference between the central conductor of the cable and the sea ground is measured and digitised with a 16-bit ADC (a Campbell datalogger) at $2 \mathrm{~s}$ intervals, but only the 30-s averages are saved. Time is controlled by the datalogger clock, which is corrected when data are collected. Experience showed, however, that this process must be improved in order to guarantee more accurate time measurement. A GPS controlled clock system is now in use.

The voltage measuring started in November 1998. However, data acquired during the first 45 days, (considered as an experimental period), were not included in this study (Monteiro Santos et al., 1999, 2000). After some technical improvements the acquisition started on February 19, 1999. This paper deals with the analysis of data acquired between February 1999 and June 2000. The main objectives are: 1) to analyse the long-term (1 year) stability of the cable, 2$)$ to characterise the probable sources of the principal variations and, 3) to obtain preliminary information related to water flow.

\section{Raw Data}

Figure 2(a) shows the voltage recorded during May 1999. The voltage fluctuates between about -1 and $2 \mathrm{~V}$ with a 
significant semidiurnal period. Examples of data acquired in quiet and disturbed days are shown in Figs. 2(b) and 2(c). Plotted in Fig. 3 is the amplitude spectrum of the data collected between December 1999 and March 2000. The spectrum is clearly dominated by peaks at periods of diurnal ( $1 \mathrm{cpd})$, semidiurnal $(2 \mathrm{cpd})$ and 8 hours $(3 \mathrm{cpd})$. All these periods correspond to the combination of tidal, motionally and geomagnetic frequencies. The presence of the semi-

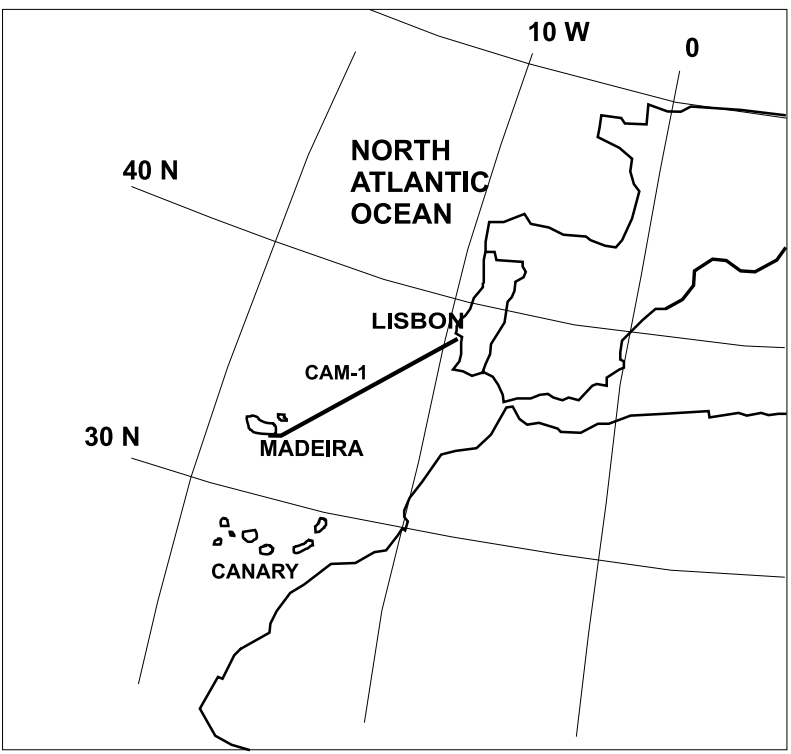

Fig. 1. Location of the CAM-1 cable lunar M2 constituent is also clearly depicted in the spectrum.

Calculation of the average value of all the available data give a value of $230.05 \pm 758.17 \mathrm{mV}$. The high value of the standard deviation arises mainly from tides and the intense geomagnetic activity recorded by the cable. The semidiurnal tidal component was then filtered by the application of a notch filter. Simple daily mean values were calculated from filtered data (Fig. 4). The average value of the daily series is $225.83 \pm 88.33 \mathrm{mV}$. The standard deviation now has a much lower value. According to Palshin et al. (2001), solar daily variations are efficiently suppressed by daily averaging procedure. In our case, due to their importance, tidal signals probably continue to be present in the averaged data and these results are not accurate measures of the integral water transport. A more detailed analysis is needed to reach that objective.

The histogram of the 30-min average values, for the interval February 1999, through to June 2000, is shown in Fig. 5. The voltages were binned in $300 \mathrm{mV}$ boxes. From the figure one can conclude that the distribution of the voltage values is not symmetrical around zero potential, being biased towards positive values. In fact, the distribution is close to a normal distribution centred at $0.217 \mathrm{~V}$.

The 30-s average values were used to determine averages over seven days and have also been averaged using a twenty day moving window. These results are plotted in Fig. 6 . The plot suggests a periodic variation. However, a more useful determination, in the sense that we can correlate it with water-flow, of the average values needs to take into account the levels of geomagnetic activity (in a preliminary study it

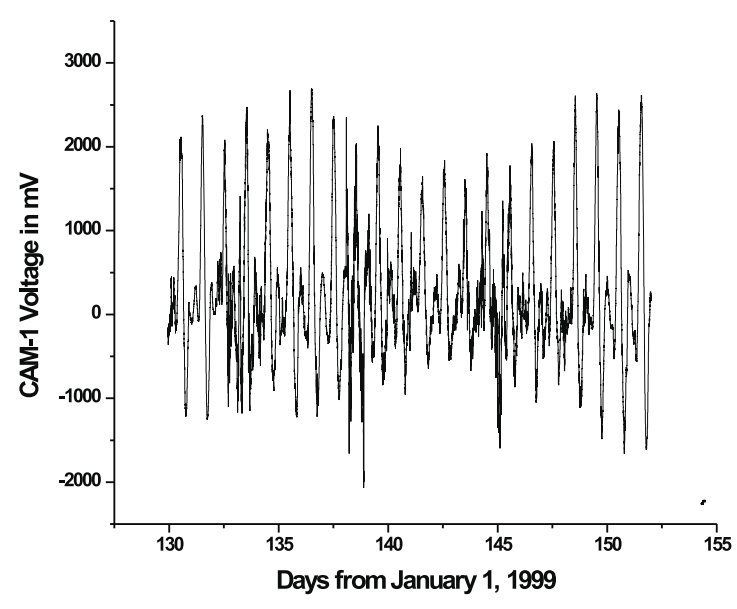

a)

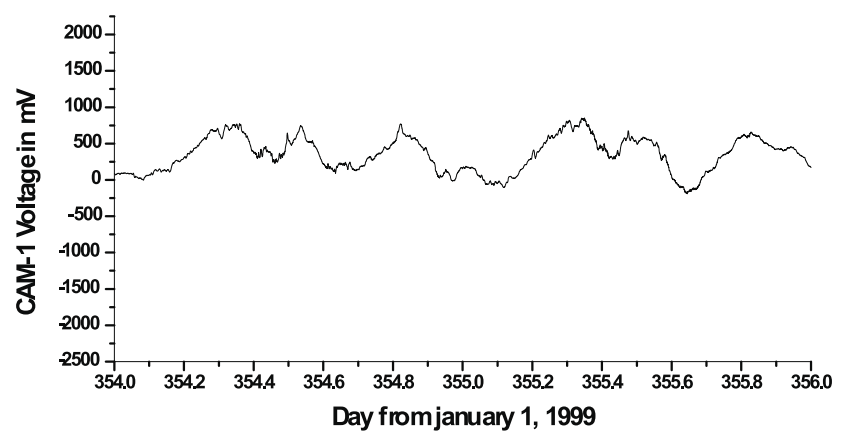

b)

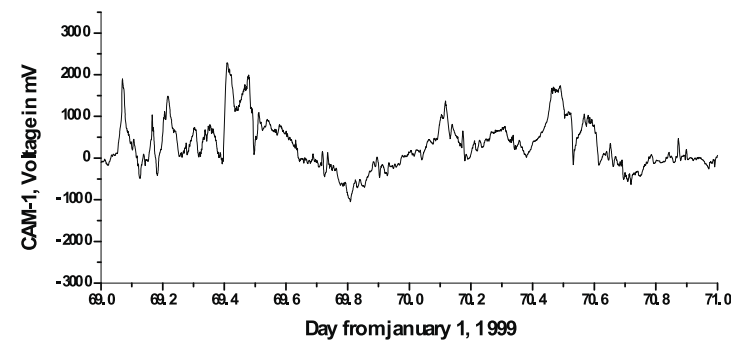

c)

Fig. 2. Examples of the measured voltage (30-s average), a) during May 1999, quiet b) and disturbed c) days. 


\section{CAM1 Cable}

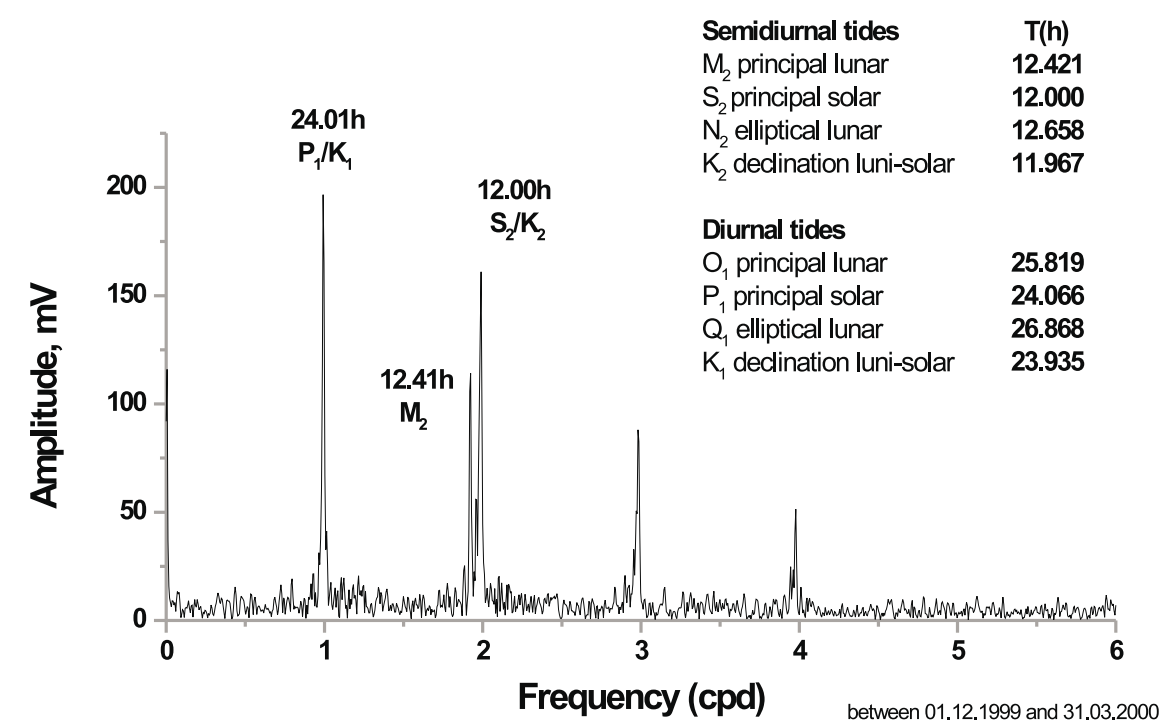

Fig. 3. Amplitude spectrum obtained from CAM-1 voltages between December 1999 and March 2000.

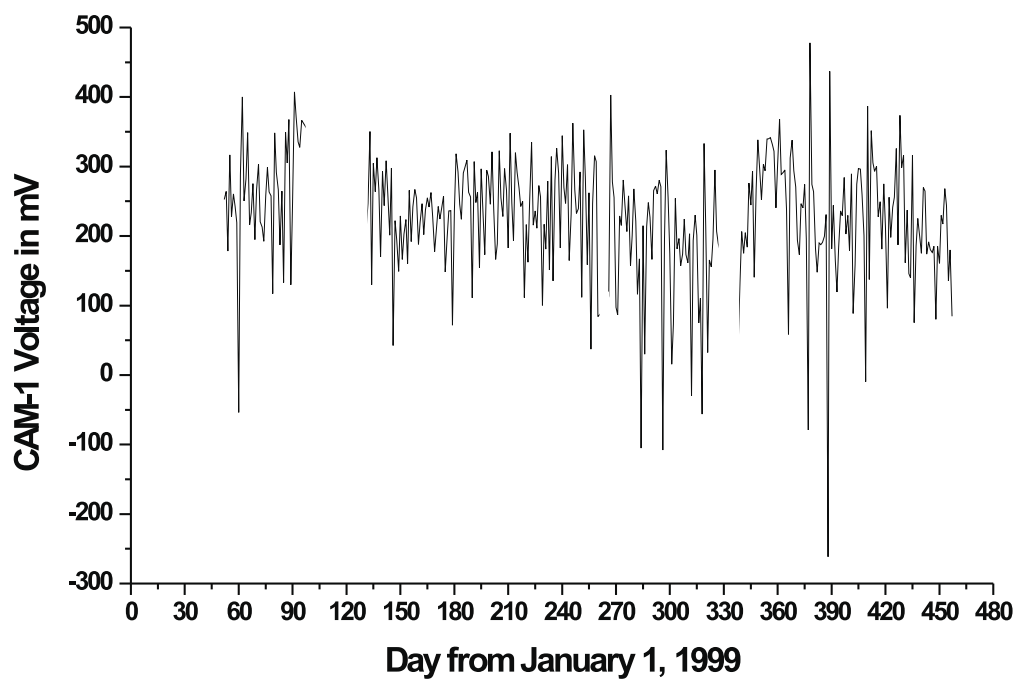

Fig. 4. Daily mean CAM-1 voltages. Data gaps can be observed in April-May, September and in November.

was found that the electric and magnetic field show a very high correlation $(>0.85)$ till periods of $120000 \mathrm{~s})$. In order to decrease the influence of the signal induced by external sources only the days with low geomagnetic activity, must be considered. These are usually estimated from daily geomagnetic indexes. Several indexes are in use, for example $\mathrm{K}, A p$, among others. Nevertheless, the published indexes only consider the quietest ten days in each month. Equivalent information, but not so restrictive, can be obtained by analysing the daily data as follows.

The difference $\delta H=H_{\text {maximum value }}-H_{\text {minimum value }}$ of the magnetic component $H$ was determined for each period of 3 hours. The eight values were then used to determine daily averages $\delta H$ of those differences. These values are used as rough estimations of the geomagnetic activity. Values less than $10 \mathrm{nT}$ were obtained on several days in January and
December, indicating that these were the quietest months in 1999. The highest values (>60 nT) were obtained on some days in September. In each month-data, those days with $\delta H<30 \mathrm{nT}$ and $<50 \mathrm{nT}$ were selected and averaged. The results obtained for the $\delta H<50 \mathrm{nT}$ condition are shown in Fig. 7. The number of days used in each calculation is shown at the bottom of the figure. The fifteen months data suggests a possible periodicity of around 120 days. There are two maxima: in the transition from winter to spring (March-April) and in summer (August-September) and two minima at the end of the spring (May-June) and in autumn (October-November). There are no enough data to define what happen in December-January.

A semiannual variation in magnetic activity level has been observed by several investigators according to Lanzerotti et al. (1992 and references therein). To clarify this point we 


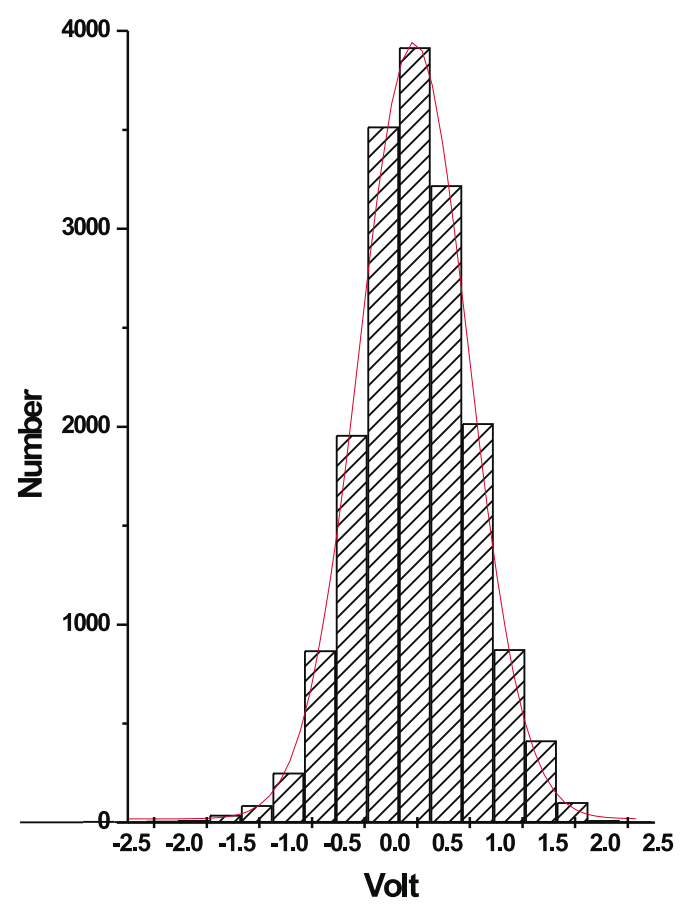

Fig. 5. Statistical distribution of 30-min mean values of the voltages measured on CAM-1 cable. The solid line represents the fit of a Gaussian distribution centred at $0.217 \mathrm{~V}$.

calculated the monthly mean of the magnetic field components from Guimar. Figure 8 shows the result for $X$ component. It can be noted that there is no correlation between the magnetic and the cable voltage signals at so long periods. Therefore, it is unlikely that the approximately 120 days variation seen in Fig. 7 has geomagnetic origin.

The results presented in Fig. 7 represent the long period variation of the cable voltage and can be used to test for possible systematics in the measurements. A drift in the electrode contact could be expected since the two terminals are made in a different way and are located in different geological (and electrical) environment. The best linear fit obtained from data in Fig. 7 (bottom) with slope of $-0.080 \pm$ $0.057 \mathrm{mV} /$ day reveals that no significant drift is observed, at least in the year interval considered.

\section{Discussion}

The average of the mean values estimated from days with $\delta H<30 \mathrm{nT}$ is $237.18 \pm 25.19 \mathrm{mV}$, that is, the mean electric field is about $0.206 \pm 0.022 \mathrm{mV} / \mathrm{km}$. This value is higher (three times larger) than that measured by Lanzerotti and his co-authors in North Atlantic (Lanzerotti et al., 1985). Our value is of the same order as the value measured by Lanzerotti in the $4000 \mathrm{~km}$ long cable between Hawaii and California (Lanzerotti et al., 1992), and with the same sign. Part of this electric field is due to electrochemical effects associated with the ground connections. The other part can be attributed to possible ocean flows across the cable. It is not possible to determine exactly the contribution of the electrochemical effects to the potential.

We will assume that the value of the mean electric field has electrochemical origin and that the long period oscillations (with amplitude of $\pm 0.022 \mathrm{mV} / \mathrm{km}$ ) can be explained
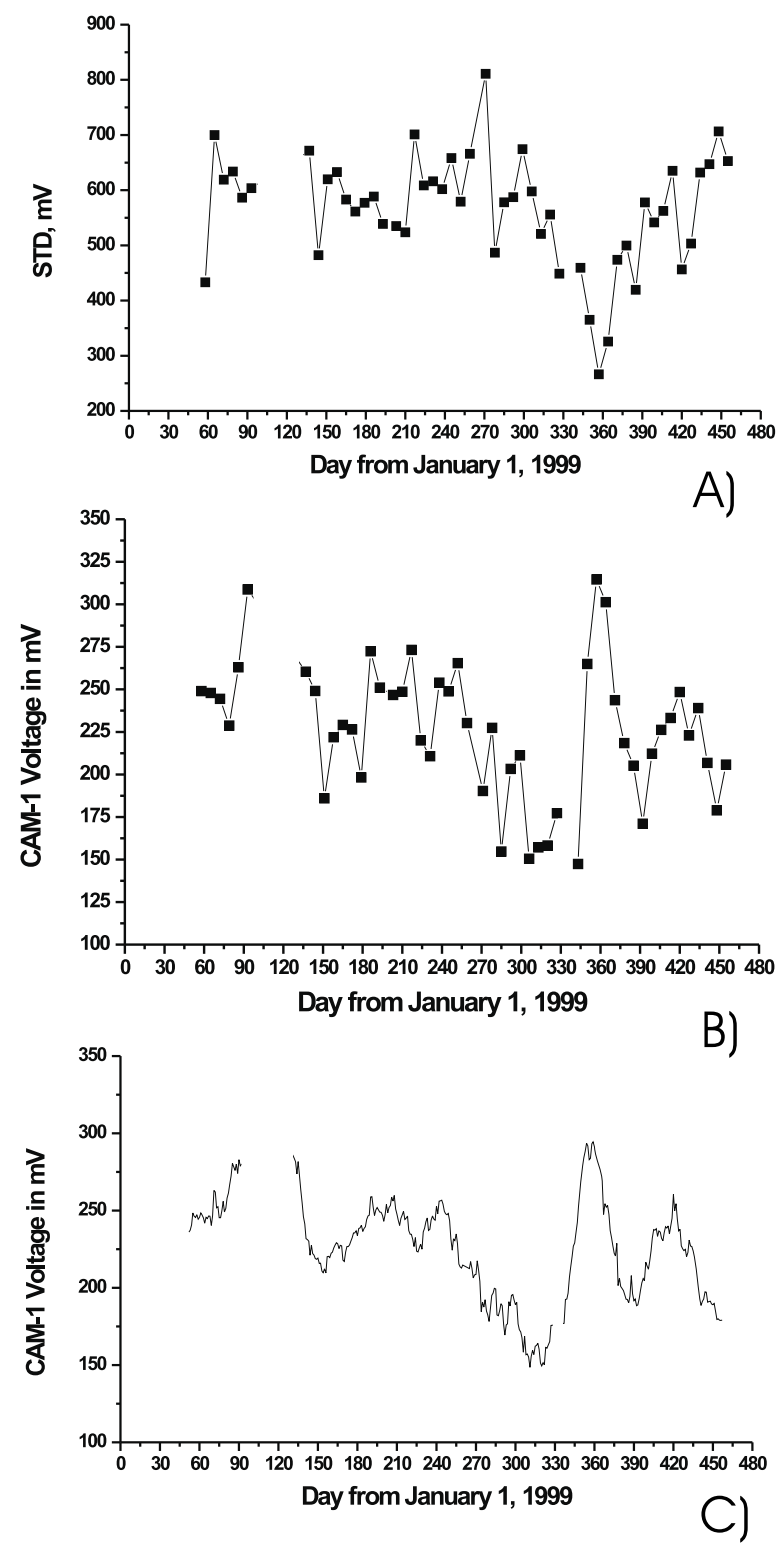

Fig. 6. Weekly mean of CAM-1 voltages (b) and their standard deviations (a). Smoothed voltages using twenty day adjacent averaging are plotted in (c).

by water transport. However, a correlation between electrical potential and water transport only can be made whether independent measurements of mass transport are available. As we do not have such measurements we will estimate a value of the vertical mean of the conductivity-weighted velocity for the total flux of water, assuming a very simple model (Sanford, 1971; Spain and Sanford, 1987). Neglecting displacement currents, self and mutual induction phenomena, depth integrated electrical currents and large-scale electric currents, the voltage induced by a flow of conductive sea water in the magnetic field of the earth can be expressed approximately by $\mathbf{E}=\mathbf{B}_{\mathbf{z}} \times \mathbf{v}$. $\mathbf{E}$ represents the horizontal electric field, $\mathbf{B}_{\mathbf{z}}$ the vertical component of the magnetic field and $\mathbf{v}$ is the mean conductivity-weighted velocity. According to the general theory of the motional induction in the sea, the mean conductivity-weighted velocity is define by (see, e.g. Spain and Sanford, 1987): 


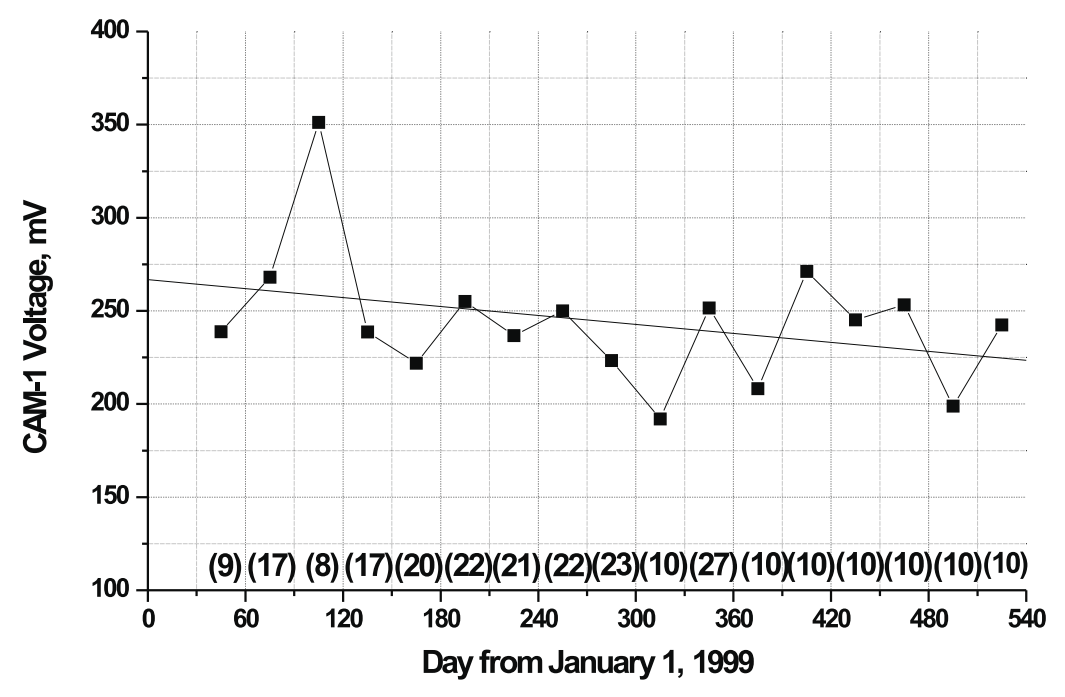

Fig. 7. Monthly mean voltages estimated using only those days with $\delta H<50 \mathrm{nT}$. The slope of the best linear fit is $-0.080 \pm 0.057 \mathrm{mV} /$ day.

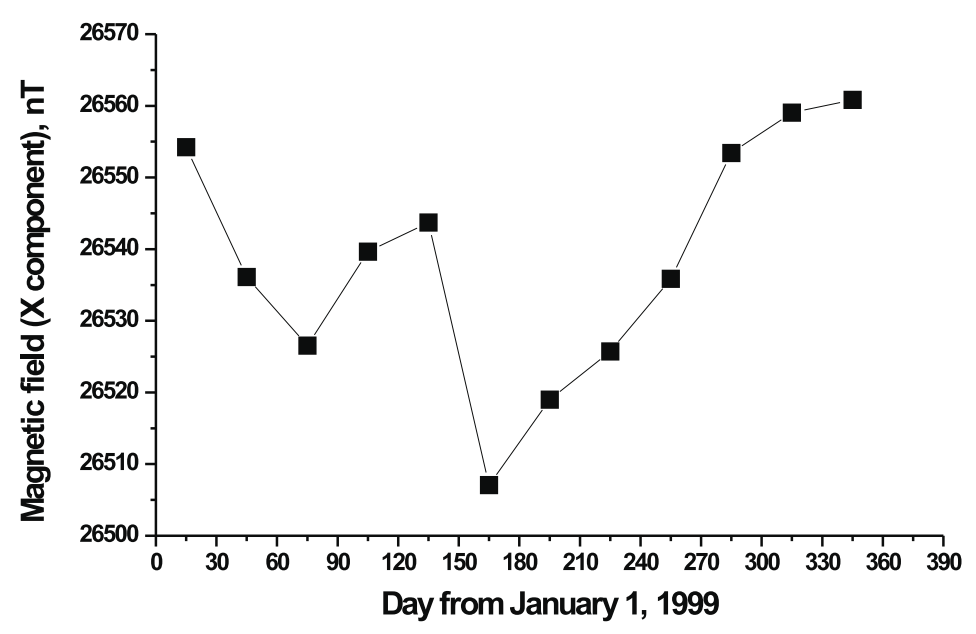

Fig. 8. Monthly mean of the north magnetic field component measured in Guimar Observatory.

$$
\mathbf{v}=\frac{\int_{-H}^{0} \sigma v d z}{\int_{-H s}^{0} \sigma d z}
$$

where $H$ is the water depth and the integral in the denominator is the conductance of the seawater and sediments down to a depth $H s$ from which no electric current flows, and $v$ is the flow through the cable. Assuming the preceding model the electric potential observed in the cable is the same as if the ocean current moved crossing the cable with a baratropic velocity of $\mathbf{v}$.

However, when using the proposed model for the interpretation of the CAM-1 cable data we must take in mind that: a) the cable data are affected by lateral currents, which pattern is unknown; b) there are downstream (and temperature) variations which pattern is completely unknown; c) the seabottom geoelectric structure is also unknown. Therefore, the application of the model can only give us a very preliminary value of the total (net) water flux through the cable. The vertical component of the earth's steady magnetic field in the region crossed by CAM-1 is $24000 \mathrm{nT}$ and the estimated value for the total flux of water is then \pm 0.09 $\mathrm{cm} / \mathrm{s}$. As mentioned, this value must be verified with other observations.

The information contained in the short period measurements is dominated by induced electromagnetic field and can be used for solid earth investigations (see, e.g. Lizarralde et al., 1995; Vanyan et al., 1998). More precisely, an estimation of the electrical resistivity with depth can be obtained. These studies, now in progress, are based on the magnetotelluric sounding theory and can be carried out with the help of the geomagnetic data from Guimar Observatory in Canary Islands.

Acknowledgments. The authors would like to thank many people at Marconi and TRIMAD who provided us the opportunity to use the cable and helped us in several ways. In particular we thank Eng. Vasco Sá, Mr. António Abrantes and Mr. Marçal from Marconi and Dr. Luís Sousa and Mr. Crisóstomo Luís from TRIMAD. Thanks are also due to Luís Matias for his interest in the subject and initial help. Comments and suggestions from the two reviewers (N. Palshin and H. Utada) contributed decisively to improve the paper and are thanked. This work was developed in the scope of 
the ISO-3D project funded by EC. Thanks to FCT for continuous supporting of the CGUL are also due.

\section{References}

Chave, A. D. and D. S. Luther, Low-frequency, motionally induced electromagnetic fields in the ocean, 1. Theory, J. Geophys. Res., 94, 71857200, 1990.

Chave, A. D., D. S. Luther, L. J. Lanzerotti, and L. V. Medford, Geoelectric field measurements on a planetary scale: oceanographic and geophysical applications, Geophys. Res. Lett., 19(13), 1411-1414, 1992.

Flosadottir, A. H., J. C. Larsen, and J. T. Smith, The Relation of Seafloor Voltages to Ocean Transports in North Atlantic Circulation Models: Model Results and Practical Considerations for Transport Monitoring, J. Phys. Oceanogr., 27, 1547-1565, 1997.

Fujii, I. and A. D. Chave, Motional induction effect on the planetary scale: geoelectric potential in the eastern North Pacific, J. Geophys. Res., 104, 1343-1359, 1999.

Fujii, I., L. J. Lanzerotti, H. Utada, H. Kinoshita, J. Kasahara, L. V. Medford, and C. G. Maclennan, Geoelectric power spectra over oceanic distances, Geophys. Res. Lett., 22, 421-424, 1995.

Lanzerotti, L. J., L. V. Medford, C. G. Maclennan, D. J. Thomson, A. Meloni, and G. P. Gregori, Measurements of the large-scale directcurrent Earth potential and possible implications for the geomagnetic dynamo, Science, 229, 47, 1985.

Lanzerotti, L. J., C. H. Sayres, L. V. Medford, J. S. Kraus, and C. G. Maclennan, Earth potential over $4000 \mathrm{~km}$ between Hawaii and California, Geophys. Res. Lett., 19(11), 1177-1180, 1992.

Larsen, J. C. and T. B. Sanford, Florida current volume transports from voltage measurements, Science, 227, 302-304, 1985.

Lizarralde, D., A. D. Chave, G. Hirth, and A. Schultz, Long period magnetotelluric study using Hawaii-to-California submarine cable data: implication for mantle conductivity, J. Geophys. Res., 100, 17837-17854, 1995

Meloni, A., L. J. Lanzerotti, and G. P. Gregori, Induction of currents in long submarine cables by natural phenomena, Rev. Geophys. Space Phys., 21, 795-803, 1983.

Monteiro Santos, F. A., A. Soares, J. M. Miranda, L. A. Mendes-Victor, and ISO3D team, Preliminary electric field observations in the CAM-1 cable between Madeira and Lisboa, Geophys. Res. Abstracts, 1(1), 180, 1999

Monteiro Santos, F. A., A. Soares, A. Flosadottir, A. Junge, L. MacGregor, J. M. Miranda, R. Nolasco, and M. Sinha, Measurements of electric potential in CAM-1 cable, $2^{a}$ Assembleia Luso Espanhola de Geodesia e Geofísica, Lagos, Portugal, 2000.

Palshin, N. A., Oceanic electromagnetic studies: a review, Surveys in Geophysics, 17, 455-491, 1996.

Palshin, N. A., L. L. Vanyan, R. D. Medzhitov, G. I. Shapiro, M. A. Evdoshenko, H. Utada, H. Shimizu, and Y. Tanaka, Use of the Nakhodka-Naoetsu Submarine Cable for Studying the Temporal Variability of the Integral Water Transport in the Sea of Japan, Oceanolgy, 41(3), 447-457, 2001.

Sanford, T. B., Temperature transport and motional induction in the Florida Current, Journal of Marine Research, 40, 621-639, 1982.

Sanford, T. B., Motionally-induced electric and magnetic fields in the sea, J. Geophys. Res., 76, 3476-3492, 1971.

Spain, P. and T. B. Sanford, Accurately monitoring the Florida Current with motionally induced voltages, Journal of Marine Research, 45, 843-870, 1987.

Vanyan, L. L., H. Utada, H. Shimizu, Y. Tanaka, N. A. Palshin, V. Stepanov, V. Kouznetsov, R. D. Medzhitov, and A. Nozdrina, Studies on the lithosphere and the water transport by using the Japan Sea Submarine Cable (JASC); 1, Theoretical considerations, Earth Planets Space, 50(1), 3542,1998 .

F. A. Monteiro Santos (e-mail: dfams@fc.ul.pt), A. Soares, L. Trindade, R. Nolasco, H. Rodrigues, and ISO-3D team 